\title{
EDITORIAL
}

\section{Do affluent societies have the only options for the best therapy?}

\section{Leukemia (2007) 21, 387-388. doi:10.1038/sj.leu.2404534}

The advent of imatinib as treatment for chronic myelogenous leukemia $(\mathrm{CML})$ has renewed attention to how payment costs in affluent countries and the developing worlds bring about different therapy recommendation in both. Financial considerations must enter discussions on clinical management of many diseases and often are as important as the clinical circumstances of the patient. These considerations have variation by country as well as by socio-economic status. Gratwohl et al. point out in this article how costs of care influence therapies patients choose or are offered vary in different European countries apparently stratified by relative wealth of the country involved., ${ }^{1,2}$ Healthcare providers do no service to patients by only offering unaffordable therapies. Risk-benefit advice given to patients must factor in patient economics. This article points identifies new implications of costs to society of targeted therapies. Superficially imatinib seems less costly than allogeneic bone marrow transplant (BMT) to the casual observer. But is it? Current knowledge indicates imatinib is a lifelong-targeted therapy that a patient may never be able to be weaned off. That has cost both to society and to an individual. Transplant while higher in initial cost outlays may still have a better lifetime economic value. This provocative study forces us to contemplate and grapple with long-term costs of therapy.

Having spoken at medical conferences in India and China and occasionally joining physicians in China on their work rounds, I have developed a different perspective on the costs of health care. In India, a little known fact is the most common type of leukemia is CML and the median age of presentation is 15 . It is unclear to most observers whether this discrepancy from the 60 plus commonly seen in the US or Europe is due to poor epidemiology data of cause of death in the elderly in India or a real population difference. Hematologists and Oncologists in India told me that lower middle class to upper class by income families could afford 1 year of imatinib. Both Indian and Chinese physicians have commented to me that 1 year of imatinib equaled the cost of an allogeneic BMT. Only the wealthiest few families can afford 2 years of imatinib for a family member. Because of the economics, allogeneic transplant is the preferred option for patients in India and China, particularly if a human leukocyte antigen genotypic identical sibling is the only potential donor.

China, while it does not have the same prevalence of $\mathrm{CML}$, will make a different decision than India. China has a small but increasing in donors unrelated transplant registry. Because of the one child policy, there are few sibling donors for potential transplant recipients. China has better outcomes with mismatch transplants than the US owing to homogeneity in the population that approaches the Japanese. The individual economic circumstances of the family there will determine which route is taken for care. Chinese families often use life savings to pay for catastrophic medical care for family members. The Chinese state provides partial funding for public health needs and access to primary care clinics, but does not routinely support catastrophic care for an individual patient. How to wisely use this limited family fund source has required Chinese families to think about whether the treatment that provides a long-term solution for the disease process. What Chinese and Indian physicians have lectured to me privately about, Gratwohl and Ruiz-Argüelles et al. ${ }^{3}$ have now described in Eastern Europe and Latin America countries.

Economics must often drive clinical decisions by health-care providers and although we as providers hate to admit this makes for health-care rationing. Whether socialistic or capitalistic, every health-care systems use surrogates to capture costs of care. To some extent we all have the same accounting issues. A complete blood count (CBC) has a trivial daily cost, but it is hard to allocate costs and depreciation for fixed costs like hepafiltered rooms and no society wants to truly acknowledge the cost of nursing care. As a consequence of accounting practices that apply the costs of fixed and intangibles to items of service that are easy to account for. From these artificial cost assessments of health care, clinical decisions are determined and ultimately some type of health-care rationing emerges as a consequence. Having this debate on real rather than fictitious resource consumption is something all societies and health-care systems must attempt or else we will achieve false economies. ${ }^{4}$

When I have rounded in hospitals in developing countries, I have seen the struggle and strong desire by physicians in those countries to apply American and European technology to alleviate misery and suffering in their patients. I have also seen first hand the consequences of the inability owing to finances to apply everything we do to patient care. The examples are relevant to this article and the inferences the data presented suggest.

Dialogue and meeting need to happen mixing developing world and developed world physicians to discuss use of technology and drugs to treat disease. Aspects of certain developed countries' technology or drugs should not be implemented in developing countries if the entire treatment plan cannot be followed in toto. Going back to my India and China experience in the hospitals where I hold visiting professorships, I have been struck that imported drugs are a major cost of therapy. Dosages of imported drugs must be lowered because either of facility or patient economic circumstances. This has untoward implications in outcome. A classic BMT example is the use of granulocyte-colony-stimulating factor (G-CSF) for mobilization and post transplant care. The dosage of G-CSF for both is often lowered in developing countries because of cost. The physicians making decisions use across the board cuts rather than doing it selectively. When G-CSF is lowered for peripheral blood progenitor cell (PBPC) collection, the product collected has less stem cells and more peripheral T cells. This impacts engraftment times and in the allogeneic setting the risk of graft-versus-host disease. Post transplant G-CSF when administered usually only hastens engraftment by 1 or 2 days, but not enough to impact survival. If cost of G-CSF is a major issue, then it should not be given post-transplant; but dosages, should if at all possible, be optimized for the PBPC collection. Another example is the Indian young child with CML. The cost of G-CSF mobilized PBPC to obtain as a source of hematopoietic progenitors is more than the cost of a conventional marrow harvest, because for the former the drugs are imported and subject to tariffs. With early first chronic 
phase CML transplants with the relapse rate of only $5-10 \%$ long term with a bone marrow harvest as the source of hematopoietic progenitors. Thus, there may be no need to go with PBPC collections for the donor, as the marrow harvest whereas old fashioned is just as good.

Knowledge transfer in use of complex procedures should not be unidirectional between the developed world physicians and the developing world physicians. When I first lectured in China in 1996, I made a statement I had to retract about use of autologous BMT in first remission for treating Hodgkin's disease. I stated "I could foresee no circumstance for use of autologous BMT in first complete remission in Hodgkin's". The Chinese physicians politely, but forcefully countered me that for parts of their economic system the cost of care is the time away from the factory or the worker's commune. China at that time did not have access to cancer chemotherapy in many small to middle size cities and rural areas. The patient and their family had to travel to large cities to receive nitrogen mustard, vincristine, prednisone, procarbazine (MOPP) or adriamycin, bleomycin, vinblastine, dactinomycin (ABVD) chemotherapy. Eight months of therapy was prohibitively expensive for stage III or IV Hodgkin's patients, but 2-3 months of MOPP or ABVD followed by an autologous transplant was cheaper and in the Chinese experience just as curative as the 8 months of outpatient chemotherapy administered in the US and western Europe. This data needs to be shared with the developed world. We could not even propose a study in the US to gain preliminary data on this care pathway, but it could be a valid care pathway even in the United States. In Mumbai, India several studies are underway in lower socio-economic status sections of the city on the cost effectiveness of breast cancer prevention strategies and technologies. The studies focus on the cost effectiveness of mammography or self-examination on early diagnosis of breast cancer. These are studies that could not be done in affluent countries with our ready access to technology and health-care providers, but are also essential in affluent countries where there are also finite funds to be spent on health care and there is a need to spend such funds judiciously. We in affluent countries, as much as developing countries, need to smartly invest in technology and not continue to overuse superfluous technology. We should pay attention to what developing countries can teach us about our technology's utility.

Those of us from affluent countries must be careful and not impose our values on clinicians from developing countries. Years ago a letter to the editor to the NEJM commented on criticism from affluent country physicians about a decision by that poor country to send a child to Western Europe for a BMT for aplastic anemia. ${ }^{5}$ The author was responding to criticism from US and western Europe that poor countries had so many more pressing health-care concerns that is was unethical to pay for high technology items like BMT. The author commented to the effect that poor children had as much right as rich children to be cured of fatal illnesses. This author correctly reminded us physicians that all people born have the same right to live, or as the teacher from my youth so poignantly stated, "We are all created imago De.". Yet we all sadly realize that no state has unlimited finances to pay for all technology to every deserving individual. This fact becomes even more evident when considering that eight monoclonal antibodies have been approved for treating either liquid or solid tumors since 1997 and three targeted therapies have been approved since 2004 . Even affluent countries will need to assess the cost-benefit ratio for drugs where health-care resources are perceived to be limitless. Prioritization probably should be given for state support of health to public health concerns. An old sounding board article once pointed out that even poor countries have populace that demand state of the art therapy be given to certain deserving members of the population regardless of finances. ${ }^{5}$ This has historically resulted in many patients obtaining care in affluent countries with the consequential loss of important funds to pay for such services. Most developing countries have as a consequence started offering such high services within their country so as to keep scarce funds within the society so that there would be more total health-care resources to pay for high priority public health needs. For drug therapy, we also have seen the alternative scenario that a country to save its populace from the scourges of human immunodeficiency virus (HIV) will manufacture drugs locally in violation of international patents. Such actions have fostered new behaviors by pharmaceutical firms to reduce the cost for HIV antiviral therapy for developing countries with substantial populations infected with HIV.

I hope this article prompts more dialogue in health services research between physicians from developing countries and affluent countries. Physicians everywhere will have to make difficult clinical decisions with their patients in context of economic restraints. Although we physicians have a moral responsibility to advocate for all patients to have access to the best possible care. We should not view all differences in clinical practice between affluent countries and the developing world as a negative. From such differences in care approach, we physicians can obtain new insights in patient care. Physicians from affluent countries and the developing world have much to teach each other. Patients throughout the world would be better served if we can facilitate this dialogue both in peer-reviewed journals and in face-to-face meetings between physicians practicing in the developed and the developing world. We all owe this to patients everywhere.

\section{Acknowledgements}

The authors wish to acknowledge A Peter Walshe of the University of Notre Dame, Department of Political Science for his review of the concepts presented and reviewed in this commentary and Ellen Bernstein for her assistance in typing the final version.

$$
\begin{array}{r}
\text { JL Gajewski and P Robinson } \\
\text { Department of Medicine, Temple University, Temple } \\
\text { University Hospital, Philadelphia, PA, USA } \\
\text { E-mail: james.gajewski@tuhs.temple.edu }
\end{array}
$$

\section{References}

1 Gratwohl A, Baldomero H, Schwendener A, Gratwohl M, UrbanoIspizua A, Frauendorfer K. Hematopoietic stem cell transplants for chronic myeloid leukemia in Europe. Impact of Cost Considerations, (Leukemia, in press).

2 Silberman G, Crosse MG, Peterson EA, Weston RC, Horowitz MM, Appelbaum F et al. Availability and appropriateness of allogeneic bone marrow transplantation for chronic myeloid leukemia in 10 countries. New Engl J Med 1994; 331: 1063-1067.

3 Ruiz-Argüelles GJ, Gómez-Almaguer D, Morales-Toquero A, Gutiérrez-Aguirre $\mathrm{CH}$, Vela-Ojeda J, García-Ruiz-Esparza MA et al. The early referral for reduced intensity stem cell transplantation in patients with $\mathrm{Ph} 1(+)$ chronic myelogenous leukemia in chronic phase in the imatinib era: results of the Latin American Cooperative Oncohematology Group (LACOHG) Prospective Multicenter Study. Bone Marrow Transplant 2005; 36: 1043-1047.

4 Gajewski JL, Foote M, Tietjen J, Melson B, Simmons A, Champlin RE. Blood and marrow transplantation compensation: perspective in payer and provider relations. Biol Blood Marrow Transplant 2004; 10: $427-432$.

5 Woolhandler S, Himmelstein DU, Labar B, Lang S. Transplanted technology: third world options and first world science. New Engl J Med 1987; 317: 504-506. 